\title{
Bisphenol A enhances adipogenic differentiation of human adipose stromal/stem cells
}

\author{
Jason F Ohlstein', Amy L Strong', John A McLachlan², Jeffrey M Gimble', \\ Matthew E Burow ${ }^{2}$ and Bruce A Bunnell ${ }^{1,3}$ \\ ${ }^{1}$ Center for Stem Cell Research and Regenerative Medicine, Tulane University School of Medicine, \\ 1430 Tulane Avenue, SL-99, New Orleans, Louisiana 70112, USA \\ ${ }^{2}$ Section of Hematology and Medical Oncology, Department of Medicine, Tulane University Health Sciences Center, \\ New Orleans, Louisiana 70112, USA \\ ${ }^{3}$ Department of Pharmacology, Tulane University School of Medicine, New Orleans, Louisiana 70112, USA
}

Correspondence should be addressed to B A Bunnell Email

bbunnell@tulane.edu

\begin{abstract}
Exposure of humans to the endocrine disrupter bisphenol A (BPA) has been associated with increased weight and obesity. However, the mechanism(s) by which BPA increases adipose tissue in humans remains to be determined. The goal of this study was to determine the effects of BPA on adipogenesis of cultured human adipose stromal/stem cells (ASCs), precursors to mature adipocytes. ASCs from three donors were cultured for either 14 or 21 days in adipogenic differentiation media containing increasing concentrations of BPA $(100 \mathrm{pM}-10 \mu \mathrm{M})$. The extent of adipogenic differentiation in the ASCs was assessed by staining with Oil Red $O$ to visualize adipogenic differentiation and then quantified by extraction and optical density measurement of the retained dye. BPA significantly enhanced adipogenesis at a concentration of $1 \mu \mathrm{M}$ after 21 days of culture. Additionally, we found that BPA increased transcription of the estrogen receptor (ER (ESR1)) and that treatment with the ER antagonist ICI 182780 , blocked the effects of BPA, indicating that BPA may act via an ER-mediated pathway. The results of molecular analyses indicated that the expression of the adipogenesis-associated genes dual leucine zipper-bearing kinase (DLK (MAP3K12)), IGF1, CCAAT/enhancer-binding protein alpha (C/EBP $\alpha(C E B P A))$, peroxisome proliferator-activated receptor gamma (PPARY (PPARG)), and lipoprotein lipase (LPL) was temporally accelerated and increased by BPA. In summary, these results indicate that BPA significantly enhances adipogenesis in ASCs through an ER-mediated pathway at physiologically relevant concentrations.
\end{abstract}

Journal of Molecular Endocrinology

(2014) 53, 345-353

\section{Introduction}

Bisphenol A (BPA) is a compound used ubiquitously in the plastic manufacturing industry for various applications, such as lining of plastic containers (Le et al. 2008), and aluminum cans (Hugo et al. 2008), receipt paper (Biedermann et al. 2010, Liao \& Kannan 2011, Liao et al. 2012), and some dental sealants

\section{Key Words}

- adipose stromal/stem cell

- bisphenol A (BPA)

- adipogenesis

- estrogen receptor

- endocrine disrupters
(Maserejian et al. 2014). BPA exposure has been linked to a wide range of negative health effects, including an increased risk of miscarriages, obesity, and cancer (Rochester 2013). Furthermore, BPA is known to accumulate in fat, with $50 \%$ of breast adipose tissue from women containing BPA (Fernandez et al. 2007). 
BPA is also an endocrine disruptor, resulting in the activation of estrogen receptors $\alpha(\mathrm{ER} \alpha)$ and $\beta(\mathrm{ER} \beta)$ (Wozniak et al. 2005, Welshons et al. 2006, Le et al. 2008, Kim et al. 2012, Li et al. 2012, Chen Zee et al. 2013). The mechanism of action of BPA is associated with its shared homology with estrogen and the upregulation of downstream targets, including peroxisome proliferator-activated receptor gamma $(P P A R \gamma(P P A R G))$ and lipoprotein lipase $(L P L)$ genes, based on results from in vitro experiments on rodents (Melzer et al. 2011). Results from previous studies have indicated that, following pretreatment with the ER antagonist ICI 182780 , BPA-induced expression of the downstream product calbindin- $\mathrm{D}_{9 \mathrm{k}}$ was inhibited (Kim et al. 2012). These results indicate that BPA signals through an ER-dependent pathway.

Despite mounting evidence from epidemiological studies documenting the link between BPA and negative health outcomes in humans, mechanistic studies in human models have been limited. Previous investigations of BPA utilizing human bone marrow-derived mesenchymal stem cells (BMSCs) have failed to demonstrate an association between BPA and an increase in adipogenesis; however, BPA treatment significantly induced lipid formation in the murine-derived preadipocyte cell line, 3T3-L1 (Masuno et al. 2005, Sargis et al. 2010, ChamorroGarcia et al. 2012). To date, no studies of BPA have been conducted in human adipose-tissue-derived stromal/stem cells (ASCs).

In this study, ASCs were utilized to test whether BPA induces adipogenesis through the upregulation of adipogenic genes in an ER-dependent manner at physiologically relevant concentrations. These results are of high relevance, as BPA has been shown to accumulate in adipose tissue and offers a potential mechanism to account for the recent association with obesity.

\section{Methods}

\section{Human subjects}

All protocols were reviewed and approved by the Institutional Review Board of the Pennington Biomedical Research Center and all human participants provided written informed consent. Human ASCs were obtained from subcutaneous abdominal adipose tissue of three Caucasian females with a BMI below 25 (average age $34.6 \pm 8.4$ and an average BMI of $22.2 \pm 1.1$; Supplementary Table 1 , see section on supplementary data given at the end of this article) undergoing elective liposuction procedures. The stemness of ASCs was characterized based on their ability to adhere to plastic, fibroblast-like morphology, ability to form colonyforming units (CFUs), expression of cell surface markers $\left(\mathrm{CD} 44^{+}, \mathrm{CD}^{+}{ }^{+}, \mathrm{CD} 105^{+}, \mathrm{CD} 166^{+}, \mathrm{CD} 34^{-}, \mathrm{CD} 45^{-}\right.$, and $\mathrm{CD}_{11 b^{-}}$), and capacity to differentiate into either adipocytes or osteoblasts as described previously (Strong et al. 2012, 2013, Bourin et al. 2013).

\section{Cell culture}

ASCs were cultured on $150 \mathrm{~cm}^{2}$ culture dishes (Nunc, Rochester, NY, USA) in complete culture media (CCM), consisting of alpha-minimal essential medium ( $\alpha$-MEM; Gibco), 20\% fetal bovine serum (FBS; Atlanta Biologicals, Lawrenceville, GA, USA), 100 units $/ \mathrm{ml}$ penicillin and $100 \mu \mathrm{g} / \mathrm{ml}$ streptomycin (P/S; Gibco), and $2 \mathrm{mM}$ L-glutamine (Gibco), and incubated at $37^{\circ} \mathrm{C}$ with $5 \%$ humidified $\mathrm{CO}_{2}$. After $24 \mathrm{~h}$, viable cells were harvested with $0.25 \%$ trypsin/1 mM EDTA and replated at the indicated densities in CCM. Media were changed every 2-3 days. Media (CCM-charcoal dextran stripped (CDS)) were made with CDS-FBS (Gemini Bio-Products, West Sacramento, CA, USA), where indicated, to provide a system to assess BPA activity without interference due to estrogen in the serum. Donors were either individually cultured or pooled and plated in triplicate, where indicated. Donors were pooled together to account for the potential variation between the donors. Pooling was achieved through plating the ASCs from all the three donors together at equivalent concentrations. For all experiments, subconfluent cells ( $\leq 70 \%$ confluent) between passages 2 and 6 were used.

\section{Adipogenic differentiation}

Plated ASCs were cultured until 70\% confluence was reached and replaced with fresh fat differentiation media (FDM), composed of $\alpha$-MEM, 20\% CDS-FBS, $0.5 \mu \mathrm{M}$ dexamethasone (Sigma), $0.5 \mathrm{mM}$ isobutylmethylxanthine (Sigma), and $50 \mu \mathrm{M}$ indomethacin (Sigma), and 1\% P/S.

\section{Treatment with BPA and ICI 182780}

BPA (Sigma) or $17 \beta$ estradiol ( $\mathrm{E}_{2} ;$ Sigma) were diluted in DMSO (vehicle) to appropriate concentrations and added to CCM-CDS or FDM. ASCs from three donors were plated in 48-well plates (Nunc) in triplicate per donor in CCM until 70\% confluence was reached and the medium was replaced with CCM-CDS or FDM containing logarithmic increments of BPA from $100 \mathrm{pM}$ to $10 \mu \mathrm{M}$, DMSO, or $10 \mathrm{nM} \mathrm{E_{2 }}$. CCM-CDS served as a negative adipogenic

Published by Bioscientifica Ltd. 
control for normalization of their FDM counterpart set at 1.0. Pooled donors were treated with BPA or $100 \mathrm{nM} \mathrm{ICI}$ 182780 (ICI; Sigma) diluted in DMSO to appropriate concentrations. ASCs receiving ICI were pretreated with ICI for $30 \mathrm{~min}$ to allow time for complete blockade of ERs before concurrent treatment with ICI and BPA.

\section{Staining and quantification}

Following either 14 or 21 days of culture, cells were fixed in formalin and stained with Oil Red O (Sigma) to detect neutral lipid vacuoles (Strong et al. 2012, 2013). Mature adipocytes accumulate lipids, which can be readily visualized using Oil Red O stain; thus, we used Oil Red O staining as a marker for adipogenesis. In particular, ASCs that had matured from stromal/stem cells to adipocytes with lipid vacuoles were assessed. Images were acquired at $10 \times$ magnification on Nikon Eclipse TE200 with a Nikon Digital Camera DXM1200F using Nikon ACT-1 Software version 2.7. After imaging, Oil Red $\mathrm{O}$ was extracted from each well with isopropanol and the optical density was read at a wavelength of $544 \mathrm{~nm}$ (FLUOstar optima, BMG Labtech, Inc., Durham, NC, USA). Values were then normalized to the protein level in each of the ASCs well established by the BCA assay (Pierce, Rockford, IL, USA).

\section{CFU-fibroblasts}

CFU-fibroblasts (CFU-F) were assessed by plating ASCs at a density of 100 cells $/ 10 \mathrm{~cm}^{2}$ in a plate containing CCM and incubated in CCM-CDS with DMSO vehicle or $1 \mu \mathrm{M}$ BPA. After 14 days, plates were rinsed with PBS and stained with $3 \%$ crystal violet (Sigma) for $30 \mathrm{~min}$. Plates were washed with PBS and then tap water. Colonies that were $2 \mathrm{~mm}^{2}$ or greater in size were counted. Each experiment was performed in triplicate.

\section{Proliferation assay}

ASCs were plated at a density of 1000 cells/well in 96-well plates (Nunc) containing CCM to assess proliferation. Proliferation was assessed on days 1, 2, 4, and 7. On the day of analysis, cells were washed with PBS and the medium was replaced with fresh PBS containing $10 \mu \mathrm{l}$ 3-[4,5-dimethylthiazol-2-yl]-2,5 diphenyl tetrazolium bromide (MTT; Invitrogen) stock solution (5 mg MTT/1 ml PBS) and the cultures were incubated for $4 \mathrm{~h}$ at $37^{\circ} \mathrm{C}$. Following incubation, $100 \mu \mathrm{l}$ SDS (Sigma) was added and incubated overnight. Following incubation, optical density absorbance was measured at a wavelength of $584 \mathrm{~nm}$ (FLUOstar optima).

\section{Quantitative RT-PCR}

ASCs were pooled and cultured for total cellular RNA extraction using the RNeasy Mini Kit. ASCs were cultured in CCM-CDM or FDM, where indicated, with or without supplementation with $1 \mu \mathrm{M}$ BPA and/or $100 \mathrm{nM}$ ICI. RNA was then purified by DNase I digestion (Invitrogen) and reverse transcribed using the SuperScript VILO cDNA synthesis kit (Invitrogen). Quantitative real-time PCR (qPCR) was carried out using the EXPRESS SYBR GreenER qPCR SuperMix Kit (Invitrogen) according to the manufacturer's instructions. Primer sets for dual leucine zipper-bearing kinase (DLK (MAP3K12)), CCAAT/enhancerbinding protein alpha $(C / E B P \alpha(C E B P A))$, insulin-like growth factor 1 (IGF1), PPAR $\gamma, L P L, A P 2$ (GTF3A), SREBP1C (SREBF1), C/EBP $\beta$ (CEBPB), ER $\alpha$ (ESR1), and ER $\beta$ (ESR2) were used to assess the expression of adipogenic genes and ERs (Supplementary Table 2, see section on supplementary data given at the end of this article). $\beta$-actin was used as an internal reference point for normalization. At the completion of the reaction, $\Delta \Delta C_{\mathrm{t}}$ was calculated to quantify mRNA expression. The $\Delta \Delta C_{\mathrm{t}}$ values for BPA-induced genes were normalized to their controls and again to baseline day 0 values.

\section{LPL western blot}

ASCs were pooled and cultured for protein collection at days 0 and 7 in FDM following treatment with DMSO vehicle or $1 \mu \mathrm{M}$ BPA. Pelleted cells were lysed with RIPA buffer (Pierce) and centrifuged for lysate collection, and protein concentration was quantified by the BCA assay (Pierce). A total of $20 \mu \mathrm{g}$ of protein were loaded on a $12 \%$ SDS-polyacrylamide gel (Invitrogen) and transferred onto nitrocellulose membranes (Invitrogen). The blots were blocked with blØk Noise Canceling Reagents (Millipore, Billerica, MA, USA) for $30 \mathrm{~min}$, probed using a primary antibody against LPL (Abcam, Cambridge, MA, USA), incubated overnight at $4{ }^{\circ} \mathrm{C}$, washed with PBS with $0.01 \%$ Tween 20 (PBST), followed by staining with a secondary antibody conjugated to HRP (Abcam), washed with PBST, and visualized with chemiluminescence reagent (Invitrogen) on ImageQuant LAS 4000 (GE Healthcare Life Science, Piscataway, NJ, USA). Rabbit anti-actin (Sigma) was used as an internal control and for normalization.

\section{Statistical analysis}

All values are expressed as mean \pm S.E.M. or s.D. The statistical differences among two or more groups were

Published by Bioscientifica Ltd. 
determined by ANOVA, followed by the post-hoc Bonferroni multiple comparison tests vs the respective control group. The statistical differences between two groups were analyzed by Student's $t$-test. Statistical significance was set at $P<0.05$. Analysis was performed using Prism (GraphPad Software, San Diego, CA, USA).

\section{Results}

\section{BPA enhances adipogenesis in human ASCs}

ASCs were differentiated into adipocytes with FDM in the presence of a vehicle (DMSO) or BPA. After 21 days, the resulting cells were fixed and stained, images were acquired, and wells were destained for quantification. ASCs treated with BPA demonstrated a 1.67 \pm 0.13 -fold increase in adipogenic differentiation following treatment with BPA $(P<0.01$; Fig. $1 \mathrm{~A}$ and $\mathrm{B})$. The effect of BPA on CFU-Fs was assessed following 14 days of culture, and selfrenewal capacity was not affected (Fig. 1C). The effect of BPA on proliferation was investigated for 7 days, and no statistically significant effect was observed (Fig. 1D).

\section{BPA enhances adipogenesis in human ASCs in a concentration-dependent manner}

ASCs were differentiated into adipocytes in the presence of DMSO vehicle, logarithmic increments of BPA from $100 \mathrm{pM}$ to $10 \mu \mathrm{M}$, or a positive control (10 nM $\mathrm{E}_{2}$ ) for 21 days. Following culture, cells were fixed, stained, imaged, and destained for quantification. ASCs treated with $100 \mathrm{nM}$ and $1 \mu \mathrm{M}$ BPA demonstrated a significant increase in adipogenesis, with a maximal response observed at a concentration of $1 \mu \mathrm{M}$ BPA $(1.67 \pm 0.13$-fold increase) with cytotoxicity observed in treatments at a concentration of $10 \mu \mathrm{M} \quad(P<0.01$; Fig. 2A and B).

To assess whether ASCs treated with BPA underwent adipogenesis at earlier time points, ASCs were treated with DMSO vehicle or BPA for 14 days. BPA increased adipogenesis with concentrations from $10 \mathrm{nM}$ to $1 \mu \mathrm{M}$ compared with DMSO vehicle-treated ASCs. A maximal response to BPA was observed at a concentration of $100 \mathrm{nM}$ with a fold increase in the lipid content of $1.38 \pm 0.06(P<0.001$; Fig. 2C).
A
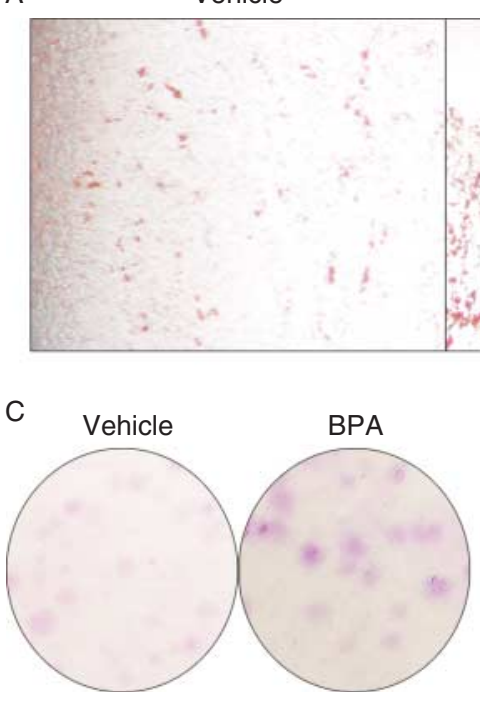

BPA
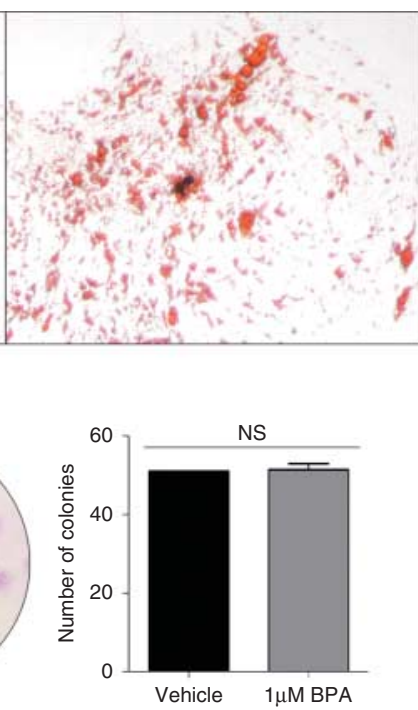

B

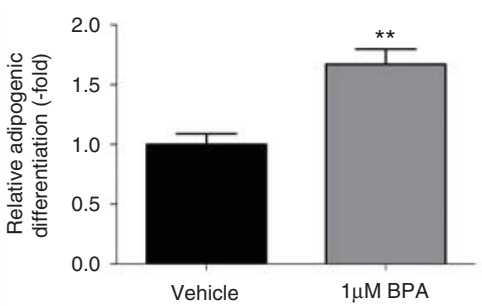

D

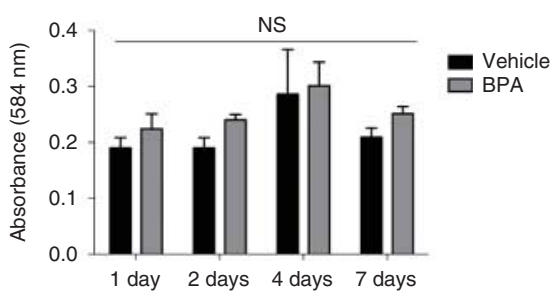

\section{Figure 1}

Characterization of adipogenesis, colony-forming units, and proliferation in response to BPA treatment in ASCs. (A) Oil Red O staining of 21-day-treated ASCs ( $n=3$ donors) with either DMSO vehicle or $1 \mu \mathrm{M}$ BPA in a fat differentiation medium. (B) Quantification of Oil Red $\mathrm{O}$ staining of ASCs ( $n=3$ donors) following 21 days of treatment with either DMSO vehicle or $1 \mu \mathrm{M}$ BPA showed a significant increase in relative lipid vacuole staining compared with vehicle treatment. (C) ASCs plated at low concentrations (100 cells/10 cm dish) and grown for 14 days before crystal violet staining for CFU-Fs, which demonstrated no significant difference between $1 \mu \mathrm{M}$ BPA treatment and treatment with DMSO vehicle. (D) MTT assay was used to assess proliferation data collected following 1, 2, 4, and 7 days of ASC treatment with either DMSO vehicle or $1 \mu \mathrm{M}$ BPA. BPA treatment did not significantly increase proliferation when compared with the vehicle. Bars, \pm s.E.M. ${ }^{*} P<0.01$. A full colour version of this figure is available via http://dx.doi.org/10.1530/JME-14-0052. http://jme.endocrinology-journals.org DOI: 10.1530/JME-14-0052
(C) 2014 Society for Endocrinology Printed in Great Britain 
BPA mediates adipogenesis through an ER-dependent pathway

RNA was collected from pooled ASCs $(n=3)$ following 7 or 14 days of treatment with $1 \mu \mathrm{M}$ BPA or DMSO vehicle in FDM. Following 7 days of treatment, BPA significantly increased baseline $E R \alpha(65.12 \pm 17, P<0.0001)$ and $E R \beta$ mRNA expression $(20.85 \pm 2.15, P<0.05$; Fig. $3 \mathrm{~A})$. Additionally, pooled ASCs were differentiated for 14 days in FDM in the presence of DMSO vehicle, $100 \mathrm{nM} \mathrm{ICI}$, and/or $1 \mu \mathrm{M}$ BPA. Following culture, cells were fixed and stained, images were acquired, and wells were destained for quantification. Treatment with BPA alone produced a $1.64 \pm 0.12$-fold increase in adipogenesis, while treatment with ICI alone did not have any effect on adipogenesis. However, upon pretreatment with ICI, BPA-induced adipogenesis was inhibited, indicating that BPA signals through an ER-dependent pathway (Fig. 3B, C, D, E and F).

\section{BPA accelerates and enhances expression of adipogenic genes}

Pooled ASCs were differentiated for 7, 14, or 21 days in FDM in the presence of DMSO vehicle or $1 \mu \mathrm{M}$ BPA, and RNA was collected for qPCR. Early, mid, and late adipogenic genes were investigated and their expression was represented as relative fold induction from their baseline values at day $0 . D L K$, expressed during the early stages of adipogenesis, showed a statistically significant $3.67 \pm 0.86$-fold increase in mRNA induction with BPA treatment on day $7(P<0.0001$, Fig. $4 \mathrm{~A})$. $C / E B P \alpha$, a marker for the mid-stage adipogenesis, showed significantly increased induction at 7 days $(7.79 \pm 0.86, P<0.01$; Fig. 4B). Late adipogenic genes including IGF1 and $L P L$ also showed significant transcript induction at 7 days $(182.45 \pm 74.63$ and $6.24 \pm 2.57$ respectively; $P<0.01$; Fig. 4C). The master transcriptional regulator of adipogenesis, PPAR, also demonstrated significant induction at 7 days $(345.66 \pm 165.21, P<0.01$; Fig. 4C). Notably, the peak induction for all genes in the vehicle-only controls was observed at day 14 or 21, when compared with day 7 in those receiving BPA treatment (Fig. 4). Other genes involved in adipogenesis including SREBP1C, AP2, and $C / E B P \beta$ were investigated, but BPA was found to have no significant effect on their expression (Supplementary Fig. 1, see section on supplementary data given at the end of this article). The greatest induction was observed in LPL mRNA levels, and this increase has to be confirmed through western blot analysis. Following 7 days of differentiation, ASCs that received BPA had a 1.77-fold increase in LPL over baseline, compared with a 1.22-fold increase in the DMSO control group (Fig. 4D). In summary, these results indicate that BPA enters into ASCs and increases the transcription of several key adipogenic genes through an ER-dependent pathway (Fig. 5).

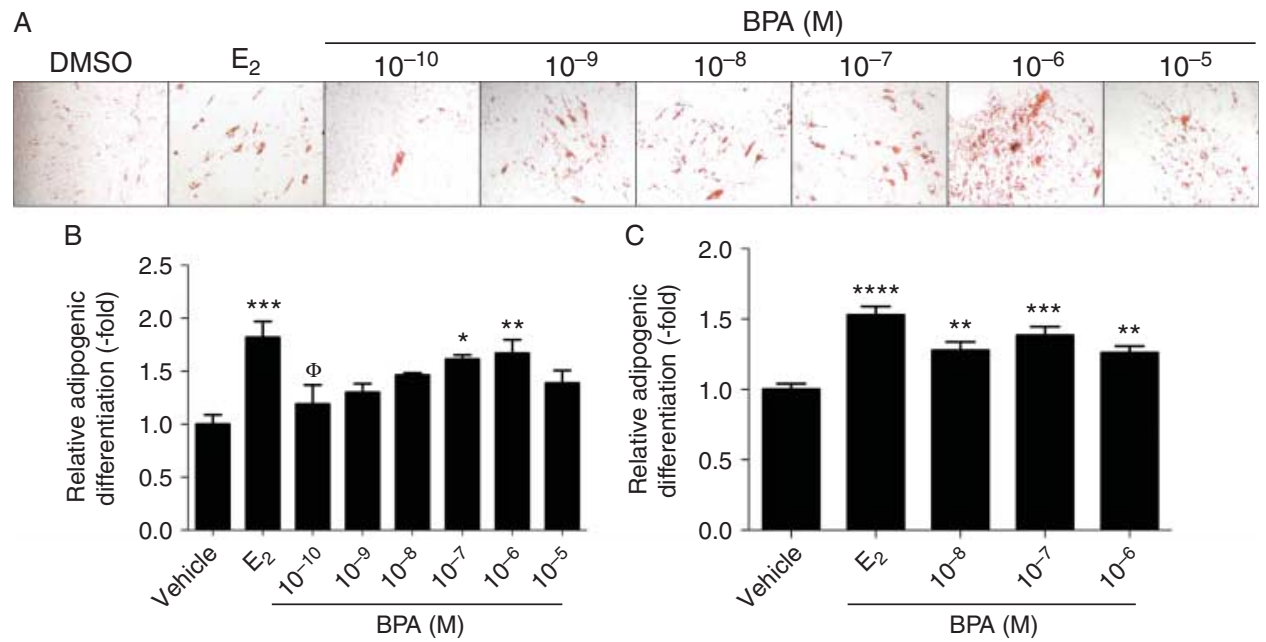

Figure 2

BPA increases ASC adipogenesis in a concentration-dependent manner. (A) Microscopy of Oil Red O staining of ASCs $(n=3)$ following 21 days of treatment with DMSO vehicle, $10 \mathrm{nM} \mathrm{E}_{2}$, or logarithmic increments of BPA from $100 \mathrm{pM}$ to $10 \mu \mathrm{M}$. $E_{2}$ was included as a positive adipogenic control. (B) Absorbance of destained 21-day-treated ASCs $(n=3)$ was quantified and showed significant increases in adipogenesis upon BPA treatment. (C) Quantification of 14-day Oil Red O destaining $(n=3)$. Bars, \pm S.E.M. $\star * * * P<0.0001, * * * P<0.001, * * P<0.01, * P<0.05$, and ${ }^{\Phi} P<0.05$.

* Is compared with BPA and $\Phi$ is compared with $E_{2}$. A full colour version of this figure is available via http://dx.doi.org/10.1530/JME-14-0052. 

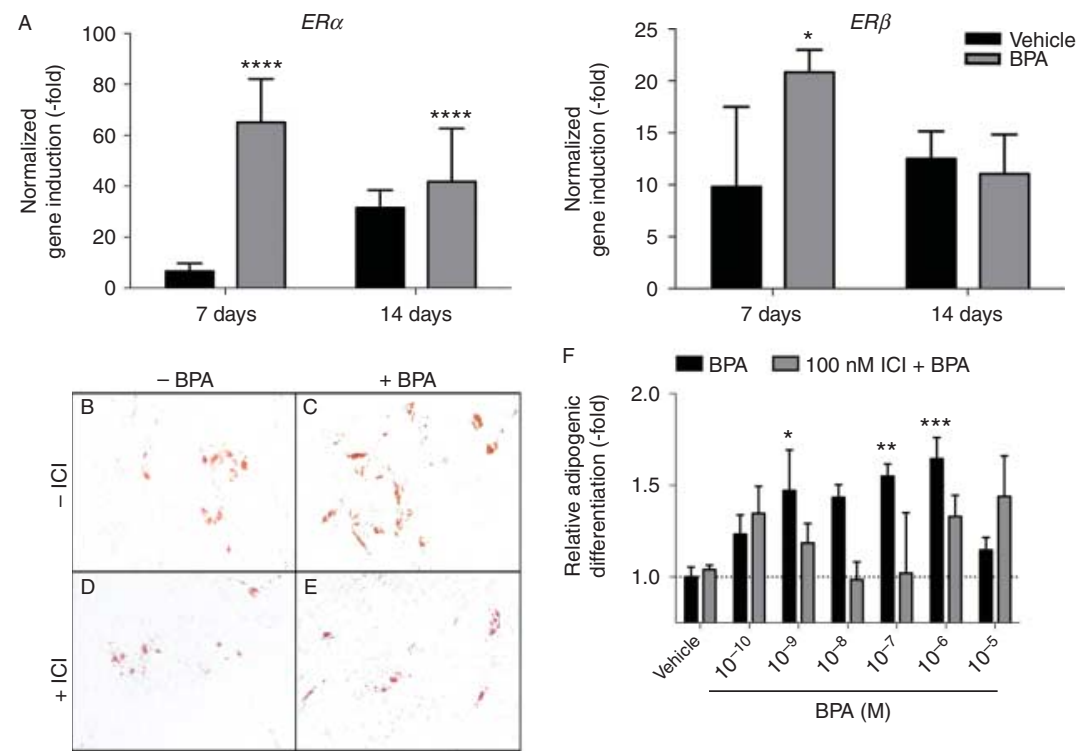

$\mathrm{F}$

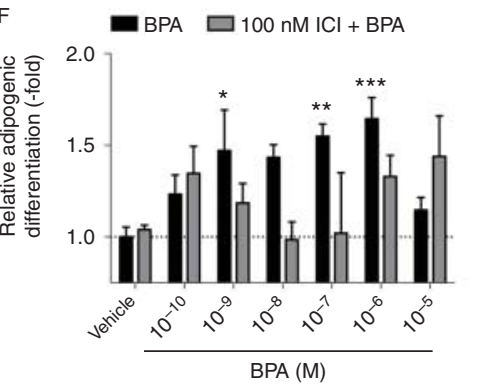

\section{Figure 3}

BPA increases adipogenesis in ASCs through an estrogen receptor (ER)dependent mechanism. (A) Induction of $E R \alpha$ and $E R \beta$ was measured in pooled ASCs $(n=3)$ treated with either $1 \mu$ M BPA or DMSO vehicle in fat differentiation media for 7, 14, or 21 days. (B) Oil Red $O$ staining of 14-day DMSO vehicle-treated pooled ASC donors $(n=3)$. (C) Staining of 14-day $1 \mu \mathrm{M}$ BPA-treated ASCs $(n=3)$. (D) Staining of 14-day $100 \mathrm{nM}$ ICI 182780 -

\section{Discussion}

The results of this study demonstrate that BPA enhances the ability of human ASCs to differentiate into adipocytes, as shown histochemically by Oil Red $\mathrm{O}$ visualization of mature adipocytes. Additionally, we have demonstrated

treated ASCs $(n=3)$. (E) Oil Red O staining of 14-day $100 \mathrm{nM} \mathrm{ICl-}$ and $1 \mu \mathrm{M}$ BPA-treated ASCs $(n=3)$. (F) Quantification of destained ASCs $(n=3)$ following treatment with either vehicle, $1 \mu \mathrm{M} \mathrm{BPA}, 100 \mathrm{nM} \mathrm{ICl}$, or logarithmic increments of BPA from $100 \mathrm{pM}$ to $10 \mu \mathrm{M}$ and $100 \mathrm{nM} \mathrm{ICI}$. Bars, \pm s.d. $* * * * P<0.0001, * * * P<0.001, * * P<0.01$, and $* P<0.05$. A full colour version of this figure is available via http://dx.doi.org/10.1530/JME-14-0052.

the increased induction of the ER and the adipogenic genes $D L K, C / E B P \alpha, I F G 1, P P A R \gamma$, and $L P L$ (Ali et al. 2013). In addition, BPA accelerates their expression with peak induction observed at day 7, when compared with day 14 of vehicle treatment. Moreover, upon treatment with the
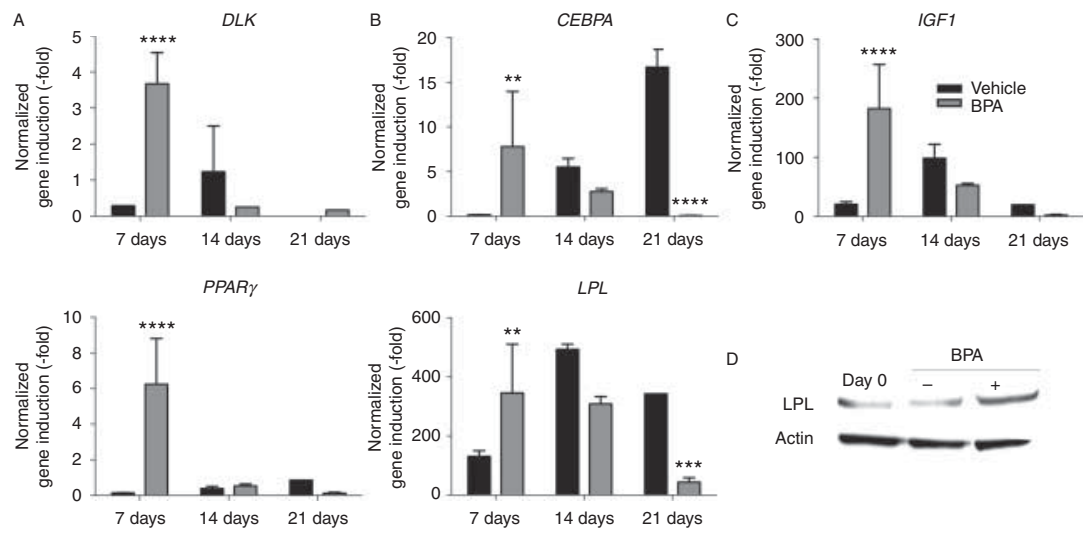

\section{Figure 4}

BPA increases and accelerates adipogenic gene induction in ASCs. (A) Induction of the early adipogenic gene marker $D L K$ was measured in pooled ASCs $(n=3)$ treated with $1 \mu \mathrm{M}$ BPA or DMSO vehicle in fat differentiation media (FDM) treated for 7,14 , or 21 days. (B) Mid adipogenic induction markers analyzed included CEBPA. (C) Late adipogenic induction markers analyzed included IGF1, PPAR $\gamma$, and LPL. (D) Western blot analysis for LPL protein levels in ASCs at baseline or following 7 days of treatment with either DMSO vehicle or $1 \mu \mathrm{M}$ BPA in FDM. Bars, \pm s.d. $* * * * P<0.0001$ and $* * P<0.01$. http://jme.endocrinology-journals.org DOI: 10.1530/JME-14-0052
(C) 2014 Society for Endocrinology Printed in Great Britain 


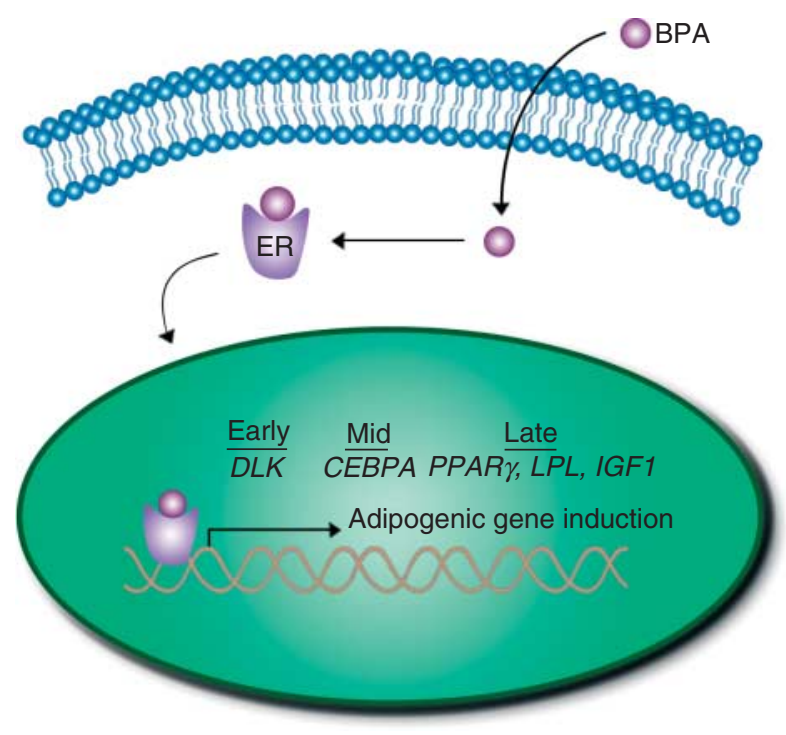

Figure 5

Representation of the effects of BPA on adipogenesis in ASCs. The diagram illustrates BPA entering into an ASC, then interacting with the ER and translocating to the nucleus, where the transcription of key adipogenic genes such as DLK, CEBPA, IGF1, PPAR $\gamma$, and LPL is increased, in turn enhancing and accelerating the path from adipose stem/stromal cell to mature adipocyte. A full colour version of this figure is available via http://dx.doi.org/10.1530/JME-14-0052.

ER antagonist ICI 182 780, the effect of BPA on adipogenic differentiation was blocked. These findings demonstrate the adipogenic effects of BPA in human ASCs and provide a potential mechanism for the association between BPA and obesity.

While the majority of the epidemiological studies of BPA and obesity demonstrate a positive association (vom Saal \& Hughes 2005, Khalil et al. 2013, Rochester 2013), molecular studies in vitro (Chamorro-Garcia et al. 2012) and in vivo (Somm et al. 2009) have generated conflicting results regarding the effects of BPA on adipogenesis. Notably, Chamorro-Garcia et al. (2012) did not observe an effect in human BMSCs upon treatment with BPA; however, the murine 3T3-L1 preadipocyte cell line responded to treatment with $100 \mathrm{nM}$ BPA with a maximal adipogenic response. Additional studies on 3T3-L1 cells demonstrated that BPA treatment increased induction of LPL (Masuno et al. 2005) and PPAR (Sargis et al. 2010). Somm et al. (2009) reported that prenatal exposure to BPA in rodents led to increased white adipose depots and increased expression of $C / E B P \alpha, P P A R \gamma$, and $L P L$. While the results of these studies are consistent with our analysis, we observed a marked induction of DLK and IGF1 mRNA transcripts. DLK expression has been linked to adipogenesis, as well as, being a target of PPAR $\gamma$ transcriptional activity (Couture \& Blouin
2011). IGF1 has been associated with obesity, insulin resistance, and adipogenesis (De Pergola \& Silvestris 2013, Xie \& Wang 2013). Additionally, out of the genes studied, we observed the largest statistically significant induction in LPL mRNA following BPA treatment. This finding was consistent with results from western blot analysis of LPL protein expression, where LPL protein increased following BPA treatment compared with treatment with DMSO vehicle.

Results of additional studies have indicated that BPA works through the activation of the ER (Wozniak et al. 2005, Welshons et al. 2006, Li et al. 2012, Chen Zee et al. 2013), with its effects being inhibited by the competitive ER antagonist ICI 182780 (Kim et al. 2012). Similarly, we observed that following BPA treatment, there was an increase in the expression of the ER and that the addition of ICI 182780 negated the effects of BPA on adipogenesis, indicating that BPA mediates its effects through ERs. Furthermore, IGF1 is induced upon activation of the ER. Thus, consistent with our results demonstrating the induction of IGF1 mRNA expression by BPA and the reduced adipogenic effects of BPA following treatment with an ER antagonist, we provide additional evidence for BPA signaling through an ER-dependent pathway (Surmacz \& Bartucci 2004, Hawsawi et al. 2013).

Results from previous studies have indicated that BPA acts as an endocrine disrupter (Wozniak et al. 2005, Welshons et al. 2006, Le et al. 2008, Kim et al. 2012, Li et al. 2012, Chen Zee et al. 2013), by signaling through the ERs and disruption of normal estrogen signaling. Our present data showing the activation of a downstream target of the ERs (IGF1) following BPA treatment and the amelioration of BPA-driven adipogenesis with ICI further support the fact that BPA acts as an exogenous chemical signaling through an endogenous pathway and, thus, as an endocrine disrupter.

Our results indicate that BPA has a maximal effect at a concentration of $1 \mu \mathrm{M}$; however, a significant increase in adipogenesis in ASCs treated for 14 days at levels as low as $100 \mathrm{pM}$ was observed. Welshons et al. (2006) reported average BPA serum levels to be between 1 and $20 \mathrm{nM}$ with BPA showing activity in cellular assays as low at $1 \mathrm{pM}$ to $1 \mathrm{nM}$. One of the key findings of this study is that while there is a robust response to BPA at 21 days, a substantial increase in transcriptional activity at day 7 was observed and increased adipogenesis at 14 days in response to lower concentrations of BPA was noted. These findings indicate that even low-level exposure to BPA can expedite differentiation of ASCs into a mature adipocytes.

Published by Bioscientifica Ltd. 
Linehan et al. (2012) have previously reported that BPA inhibits triglyceride accumulation in differentiating human adult stem cells through decreasing LPL expression. This study differs from that by Linehan and colleagues in that our results demonstrate that BPA accelerates adipogenesis through increasing the expression of a number of genes including $L P L$. This finding was supported by the results of western blot analysis indicating an increase in LPL protein expression following BPA treatment. Notably, our study differed in the use of an estrogen-free environment using charcoal dextrin stripped media. Additionally, we used an 80-fold lower concentration of BPA, as we observed a maximal effect at a concentration of $1 \mu \mathrm{M}$ and observed cell death at a concentration of $10 \mu \mathrm{M}$.

Taken as a whole, our Oil Red O data indicate that BPA has the ability to enhance adipogenic differentiation of ASCs into mature adipocytes. Furthermore, the enhanced and expedited expression of the ERs and adipogenic genes indicates a role for BPA in adipogenesis. Furthermore, our data indicating that these effects are caused by ERs demonstrate that BPA is acting as an endocrine disrupter (Fig. 5).

In summary, these results present a novel demonstration of BPA's role as an endocrine disrupter and its effect on adipogenesis in a human cell model. Additionally, transcriptional targets and potential pathways through which BPA mediates its effects at environmentally relevant concentrations were described, providing a possible mechanism for the evidence from a mounting number of epidemiological studies linking BPA to negative health outcomes. Additionally, given the wide use of BPA in water bottles, canned goods, and dental sealants and the tendency for BPA to accumulate in fat, this study demonstrating enhanced adipogenesis and induction of adipogenic genes in ASCs has direct implications for the ongoing obesity epidemic.

\section{Supplementary data}

This is linked to the online version of the paper at http://dx.doi.org/10.1530/ JME-14-0052.

\section{Declaration of interest}

J M G is a co-founder, co-owner, and Chief Scientific Officer of LaCell, LLC.

\section{Funding}

This work was supported by the Tulane University School of Medicine Pilot Grant.

\section{References}

Ali AT, Hochfeld WE, Myburgh R \& Pepper MS 2013 Adipocyte and adipogenesis. European Journal of Cell Biology 92 229-236. (doi:10.1016/ j.ejcb.2013.06.001)

Biedermann S, Tschudin P \& Grob K 2010 Transfer of bisphenol A from thermal printer paper to the skin. Analytical and Bioanalytical Chemistry 398 571-576. (doi:10.1007/s00216-010-3936-9)

Bourin P, Bunnell BA, Casteilla L, Dominici M, Katz AJ, March KL, Redl H, Rubin JP, Yoshimura K \& Gimble JM 2013 Stromal cells from the adipose tissue-derived stromal vascular fraction and culture expanded adipose tissue-derived stromal/stem cells: a joint statement of the International Federation for Adipose Therapeutics and Science (IFATS) and the International Society for Cellular Therapy (ISCT). Cytotherapy 15 641-648. (doi:10.1016/j.jcyt.2013.02.006)

Chamorro-Garcia R, Kirchner S, Li X, Janesick A, Casey SC, Chow C \& Blumberg B 2012 Bisphenol A diglycidyl ether induces adipogenic differentiation of multipotent stromal stem cells through a peroxisome proliferator-activated receptor gamma-independent mechanism. Environmental Health Perspectives 120 984-989. (doi:10.1289/ehp. 1205063)

Chen Zee E, Cornet P, Lazimi G, Rondet C, Lochard M, Magnier AM \& Ibanez G 2013 Impact of endocrine disrupting chemicals on birth outcomes. Gynécologie, Obstétrique \& Fertilité 41 601-610. (doi:10.1016/ j.gyobfe.2013.08.012)

Couture JP \& Blouin R 2011 The DLK gene is a transcriptional target of PPAR $\gamma$. Biochemical Journal 438 93-101. (doi:10.1042/ BJ20101840)

De Pergola G \& Silvestris F 2013 Obesity as a major risk factor for cancer. Journal of Obesity 2013 291546. (doi:10.1155/2013/291546)

Fernandez MF, Arrebola JP, Taoufiki J, Navalon A, Ballesteros O, Pulgar R, Vilchez JL \& Olea N 2007 Bisphenol-A and chlorinated derivatives in adipose tissue of women. Reproductive Toxicology 24 259-264. (doi:10.1016/j.reprotox.2007.06.007)

Hawsawi Y, El-Gendy R, Twelves C, Speirs V \& Beattie J 2013 Insulin-like growth factor - oestradiol crosstalk and mammary gland tumourigenesis. Biochimica et Biophysica Acta 1836 345-353. (doi:10.1016/ j.bbcan.2013.10.005)

Hugo ER, Brandebourg TD, Woo JG, Loftus J, Alexander JW \& BenJonathan N 2008 Bisphenol A at environmentally relevant doses inhibits adiponectin release from human adipose tissue explants and adipocytes. Environmental Health Perspectives 116 1642-1647. (doi:10.1289/ehp.11537)

Khalil N, Ebert JR, Wang L, Belcher S, Lee M, Czerwinski SA \& Kannan K 2013 Bisphenol A and cardiometabolic risk factors in obese children. Science of the Total Environment 470-471C 726-732. (doi:10.1016/ j.scitotenv.2013.09.088)

Kim SM, Jung EM, An BS, Hwang I, Vo TT, Kim SR, Lee SM, Choi KC \& Jeung EB 2012 Additional effects of bisphenol A and paraben on the induction of calbindin- $\mathrm{D}_{9 \mathrm{~K}}$ and progesterone receptor via an estrogen receptor pathway in rat pituitary GH3 cells. Journal of Physiology and Pharmacology 63 445-455.

Le HH, Carlson EM, Chua JP \& Belcher SM 2008 Bisphenol A is released from polycarbonate drinking bottles and mimics the neurotoxic actions of estrogen in developing cerebellar neurons. Toxicology Letters 2 149-156. (doi:10.1016/j.toxlet.2007.11.001)

Li Y, Burns KA, Arao Y, Luh CJ \& Korach KS 2012 Differential estrogenic actions of endocrine-disrupting chemicals bisphenol A, bisphenol AF, and zearalenone through estrogen receptor $\alpha$ and $\beta$ in vitro. Environmental Health Perspectives 120 1029-1035. (doi:10.1289/ehp.1104689)

Liao C \& Kannan K 2011 Widespread occurrence of bisphenol A in paper and paper products: implications for human exposure. Environmental Science \& Technology 45 9372-9379. (doi:10.1021/ es202507f) 
Liao C, Liu F \& Kannan K 2012 Bisphenol S, a new bisphenol analogue, in paper products and currency bills and its association with bisphenol A residues. Environmental Science \& Technology 46 6515-6522. (doi:10.1021/es300876n)

Linehan C, Gupta S, Samali A \& O'Connor L 2012 Bisphenol A-mediated suppression of LPL gene expression inhibits triglyceride accumulation during adipogenic differentiation of human adult stem cells. PLOS ONE 7 e36109. (doi:10.1371/journal.pone.0036109)

Maserejian NN, Shrader P, Brown OA, Trachtenberg FL, Soncini J, Hauser R \& Shenker BJ 2014 Dental sealants and composite restorations and longitudinal changes in immune function markers in children. International Journal of Paediatric Dentistry 24 215-225. (doi:10.1111/ipd.12064)

Masuno H, Iwanami J, Kidani T, Sakayama K \& Honda K 2005 Bisphenol A accelerates terminal differentiation of 3T3-L1 cells into adipocytes through the phosphatidylinositol 3-kinase pathway. Toxicological Sciences 84 319-327. (doi:10.1093/toxsci/kfi088)

Melzer D, Harries L, Cipelli R, Henley W, Money C, McCormack P, Young A, Guralnik J, Ferrucci L, Bandinelli S et al. 2011 Bisphenol A exposure is associated with in vivo estrogenic gene expression in adults. Environmental Health Perspectives 119 1788-1793. (doi:10.1289/ehp.1103809)

Rochester JR 2013 Bisphenol A and human health: a review of the literature. Reproductive Toxicology 42C 132-155. (doi:10.1016/j. reprotox.2013.08.008)

vom Saal FS \& Hughes C 2005 An extensive new literature concerning lowdose effects of bisphenol A shows the need for a new risk assessment. Environmental Health Perspectives 113 926-933. (doi:10.1289/ehp.7713)

Sargis RM, Johnson DN, Choudhury RA \& Brady MJ 2010 Environmental endocrine disruptors promote adipogenesis in the 3T3-L1 cell line through glucocorticoid receptor activation. Obesity 18 1283-1288. (doi:10.1038/oby.2009.419)
Somm E, Schwitzgebel VM, Toulotte A, Cederroth CR, Combescure C, Nef S, Aubert ML \& Huppi PS 2009 Perinatal exposure to bisphenol a alters early adipogenesis in the rat. Environmental Health Perspectives 117 1549-1555. (doi:10.1289/ehp.11342)

Strong A, Semon J, Strong T, Santoke T, Zhang S, McFerrin H, Gimble J \& Bunnell B 2012 Obesity-associated dysregulation of calpastatin and MMP-15 in adipose-derived stromal cells results in their enhanced invasion. Stem Cells 30 2773-2783. (doi:10.1002/stem.1229)

Strong A, Strong T, Rhodes L, Semon J, Zhang X, Shi Z, Zhang S, Gimble J, Burow M \& Bunnell B 2013 Obesity associated alterations in the biology of adipose stem cells mediate enhanced tumorigenesis by estrogen dependent pathways. Breast Cancer Research 15 R102. (doi:10.1186/ bcr3569)

Surmacz E \& Bartucci M 2004 Role of estrogen receptor alpha in modulating IGF-I receptor signaling and function in breast cancer. Journal of Experimental \& Clinical Cancer Research 23 385-394.

Welshons WV, Nagel SC \& vom Saal FS 2006 Large effects from small exposures. III. Endocrine mechanisms mediating effects of bisphenol A at levels of human exposure. Endocrinology 147 S56-S69. (doi:10.1210/ en.2005-1159)

Wozniak AL, Bulayeva NN \& Watson CS 2005 Xenoestrogens at picomolar to nanomolar concentrations trigger membrane estrogen receptor- $\alpha$ mediated $\mathrm{Ca}^{2+}$ fluxes and prolactin release in GH3/B6 pituitary tumor cells. Environmental Health Perspectives 113 431-439. (doi:10.1289/ ehp.7505)

Xie L \& Wang W 2013 Weight control and cancer preventive mechanisms: role of insulin growth factor-1-mediated signaling pathways. Experimental Biology and Medicine 238 127-132. (doi:10.1177/ 1535370213477602)

Received in final form 2 July 2014

Accepted 20 August 2014

Accepted Preprint published online 20 August 2014
(C) 2014 Society for Endocrinology Printed in Great Britain
Published by Bioscientifica Ltd. 